\title{
Inflammatory natalizumab-associated PML: baseline characteristics, lesion evolution and relation with PML-IRIS
}

Mike P. Wattjes ${ }^{1}$, Martijn T. Wijburg ${ }^{1,2}$, Jeroen van Eijk ${ }^{3}$, Stephan Frequin ${ }^{4}$, Bernard MJ Uitdehaag ${ }^{2}$, Frederik Barkhof ${ }^{1,5}$, Clemens Warnke ${ }^{6,7}$, Joep Killestein ${ }^{2}$, on behalf of the Dutch-Belgian Natalizumabassociated PML study group.

1. Department of Radiology and Nuclear Medicine, Neuroscience Amsterdam, VUmc MS Center Amsterdam, VU University Medical Center, Amsterdam, The Netherlands

2. Department of Neurology, Neuroscience Amsterdam, VUmc MS Center Amsterdam, VU University Medical Center, Amsterdam, The Netherlands

3. Department of Neurology, Jeroen Bosch Ziekenhuis, 's Hertogenbosch, The Netherlands

4. Department of Neurology, St. Antonius Hospital, Nieuwegein, The Netherlands

5. Institutes of Neurology and Healthcare Engineering, UCL, London, UK

6. Department of Neurology, Medical Faculty, University of Düsseldorf, Düsseldorf, Germany

7. Department of Neurology, University Hospital of Cologne, Cologne, Germany

Manuscript type: Research article

\section{Correspondence:}

Mike P. Wattjes

MS Center Amsterdam

Department of Radiology \& Nuclear Medicine

VU University Medical Center

De Boelelaan 117

1081 HV Amsterdam, The Netherlands

Phone: +31-20-444 4594

Fax: +31-20-444 0397

E-mail:m.wattjes@vumc.nl

Key words: multiple sclerosis, magnetic resonance imaging, progressive multifocal leukoencephalopathy, natalizumab

\section{Word count:}

Number of characters in title: 100

Number of words in abstract: 200

Number of words in body of manuscript (not including abstract, references, legends): 2636

Number of references: $\quad 39$

Number of figures: $\quad 2$ Number of color figures: $\quad 0$

Number of tables: $\quad 2$ 


\section{ABSTRACT}

Background and objective Natalizumab-associated progressive multifocal leukoencephalopathy (NTZ-PML) patients may show imaging signs suggestive of inflammation at diagnosis ("inflammatory PML"), reminiscent of PML-immune reconstitution inflammatory syndrome (PML-IRIS). We investigated the imaging characteristics of inflammatory NTZ-PML lesions and PML-IRIS to determine differentiating and overlapping features.

Methods We scored the presence, localization and pattern of imaging characteristics of inflammation on brain MRI scans of inflammatory NTZ-PML patients. The imaging characteristics were followed-up until the occurrence of PML-IRIS.

Results 10 out of the 44 NTZ-PML patients included showed signs suggestive of inflammation at time of diagnosis. The inflammation pattern at diagnosis was similar to the pattern seen at PML-IRIS, with contrast-enhancement representing the most frequent sign of inflammation (90\% at diagnosis, $100 \%$ at PML-IRIS). However, the severity of inflammation differed, with absence of swelling and low frequency of perilesional edema (10\%) at diagnosis, as compared to the PML-IRIS stage.

Conclusion Patterns of inflammation at the time of PML-diagnosis and at the PML-IRIS stage overlap, but differ in their severity of inflammation. This supports histopathological evidence that the inflammation seen at both stages of the same disease share a similar underlying pathophysiology, representing the immune response to the $\mathrm{JC}$ virus to a variable extend. 


\section{INTRODUCTION}

Progressive multifocal leukoencephalopathy (PML) is a serious side effect of immunosuppressive therapies particularly seen in multiple sclerosis (MS) patients treated with natalizumab (NTZ, Biogen Inc, Cambridge, MA, USA), a humanized monoclonal antibody against the a4-integrin adhesion molecule.[1,2] PML is an opportunistic infection of the central nervous system (CNS) caused by reactivation and replication of JC virus (JCV), characterized by a lytic infection of oligodendrocytes, astrocytes and neuronal cells.[3-5] PML risk mitigation programs during therapy with NTZ recommend regular clinical assessment, laboratory tests (eg, JCV serostatus), and magnetic resonance imaging (MRI), aiming at improving the benefit-risk ratio of a drug with a known high clinical and MRI efficacy in MS.[6-9]

In NTZ-treated MS patients, brain MRI can detect opportunistic infections such as PML at very early stages, even prior to the development of clinical symptoms suggestive of PML coining the term presymptomatic or asymptomatic PML.[10-14] However, the detection of PML at an early stage can be challenging since the imaging findings can be subtle, fluctuating and difficult to interpret.[15-19] In comparison to classical, human immunodeficiency virus (HIV) associated cases of PML, NTZ-PML displays a higher frequency of MR imaging signs suggestive of inflammation at time of diagnosis, including contrast-enhancement and punctuate lesions with a perivascular distribution pattern, reported in approximately $30 \%$ of the patients $[11,15,16]$. Such lesions can be the most prominent initial imaging sign at the time of PML diagnosis, even in asymptomatic NTZ-PML, reflecting inflammation in the perivascular spaces and thereby unmasking the opportunistic infection.[19-22] These observations have led to the term "inflammatory PML", thereby differentiating these PML cases from those without any signs of inflammation, termed "classical PML".[18,23,24] It has been suggested that the inflammation in NTZ-PML is caused by the mode of action of a drug that is classified as a selective immune suppressant, with a partial maintenance of immune functions in the central nervous system.[25] 
"Inflammatory PML" shares several imaging and histopathological characteristics with PML- immune reconstitution inflammatory syndrome (IRIS). [20,21] PML-IRIS is characterized by a clinical deterioration despite partial or full recovery of the immune competence in previously immune-compromised patients.[22,26-30] Inflammatory PML and PML-IRIS often are not clearly separated, and terminology is partly conflicting in published literature. In "inflammatory PML", lytic infection by JCV is supposed to be the leading cause of structural brain damage, and inflammation a rather desirable side action of a still partly functioning immune system limiting the further spread of, and supporting the destruction by the virus. In contrast, during PML-IRIS, the immune reactions, initiated by the JCV replicating but then spreading and becoming an independent factor of tissue destruction, is believed to overshoot and become the leading cause of structural brain damage. Thus, the correct interpretation and recognition of the two distinct variants of inflammation could affect management and treatment of patients with PML.[31,32]

Systematic data on the lesion evolution of inflammatory PML lesions, and criteria for separation from PML-IRIS are lacking. The aim of this study was to investigate characteristics of inflammatory PML and PML-IRIS, including the lesion evolution in patients with and without signs of inflammation at time of diagnosis. 


\section{PATIENTS AND METHODS}

\section{Standard protocol approvals, registrations, and patient consents}

Brain MRI is included in the standard patient care of NTZ-treated MS patients for treatment efficacy assessment and safety monitoring purposes. We retrospectively collected clinical, laboratory and imaging data from NTZ-PML patients. We obtained a waiver from our local institutional review board stating that the requirements of the Medical Research Involving Human Subjects Act did not apply and that official IRB approval was not mandatory. Written informed consent was obtained from all participants for the use of the clinical, laboratory and imaging data for research and teaching purposes.

\section{Study design, patient selection}

This retrospective study used routine brain MR images for the diagnosis and followup of PML lesions in NTZ-treated MS patients. We obtained data from 67 natalizumabassociated PML patients, 25 of whom were derived from the Dutch-Belgian natalizumabassociated PML cohort and 42 patients referred by other institutions to our center for second opinion and research purposes. Figure 1 gives detailed information on the patient selection and inclusion process. MR images were collected in the Digital Imaging and Communication in Medicine (DICOM 3) file format. All MRI scans from the first observation of PML lesions through follow-up until and including PML-IRIS stage were collected. Only patients fulfilling the following criteria were analyzed for the purpose of this study: 1 . Availability of T2weighted and contrast-enhanced T1-weighted images at the time of diagnosis, and during PML follow-up. 2. MR images of sufficient quality, suitable for diagnostics purposes (i.e., no movement artefacts or bad repositioning etc.). 3. Sufficient data available at diagnosis and during the clinical course to enable assessment of the detection of imaging findings suggestive of PML-IRIS.[33] 


\section{Image analysis and interpretation}

All MRI scans were analyzed on a digital workstation in consensus by two raters (MPW, MTW) with special expertise in the field of inflammatory diseases of the CNS. Brain MRI scans were screened for signs suggestive of inflammation at the time of PML diagnosis, before immune reconstitution (“inflammatory PML").

Imaging characteristics suggestive of inflammation were categorized as recently described [33]: 1. Occurrence of contrast enhancement in the brain. 2. Occurrence of lesions showing new signs of mass effect and/or perilesional edema. Per definition: subtle perilesional edema can present without any mass effect or swelling. 3. Occurrence of new punctate T2 lesions with a perivascular spread. The characteristics of contrast-enhancement were further classified according to the localization (in the center of PML lesions, in the border of PML lesions, outside of PML lesions with a perivascular spread, or outside of PML lesions without a perivascular spread), and the enhancement pattern (punctuate, homogeneous, patchy).

In patients showing signs of inflammation at the time of PML diagnosis, the evolution of MRI findings were assessed on follow-up MRI scans up to, and including PML-IRIS stage. Patients were considered to fulfill the PML-IRIS stage when both clinical deterioration, and new or progressive imaging signs of inflammation were noted on MRI after NTZ cessation.[23,26,27,33] The MRI analysis on the follow-up visits included: 1: Lesion evolution of the main PML lesions (size increase, decrease, stable). 2. contrastenhancement: increase, decrease or stable contrast-enhancement of pre-existing lesion, new contrast-enhancing lesion, change of the enhancement pattern. 3. New small T2 lesions with a perivascular distribution pattern 4. New mass effect and/or edema.

\section{MRI protocols}

Since the PML cases were collected from different centers, the image acquisition parameters including pulse sequences, head coils and magnetic field strengths (1.5T and 
3T) and parameters related to spatial resolution were heterogeneous and based on local MRI protocols. In all patients the MRI protocol at the time of first PML lesion detection and during follow-up, including the PML-IRIS stage, consisted of T2-weighted, T2-fluid attenuated inversion recovery (FLAIR), and post-contrast T1-weighted MR images. In 17 patients, precontrast T1-weighted images were also available during follow-up. Based on the multi-center data acquisition, the scan intervals of follow-up MRI after the diagnosis of PML were not standardized and ranged from 1 to 4 weeks. 


\section{RESULTS}

\section{Patients}

Of the screened 67 natalizumab-associated PML patients, 44 patients were eligible for analysis. Nineteen patients were excluded due to insufficient data available during followup of the PML disease course and two were excluded due to insufficient data available at PML diagnosis (inclusion criterion 3). Two patients were excluded due to insufficient quality of the MR images (inclusion criterion 2). Among the included patients, only the 10 patients that showed imaging signs of inflammation at the time of PML diagnosis were selected for the purpose of this study (figure 1). The demographic and clinical information of these 10 patients are presented in table 1, including the diagnostic classification according to PML diagnostic criteria as proposed in a consensus statement from the American Academy of Neurology (AAN) Neuroinfectious Disease Section [34].

With respect to the treatment history before the initiation of natalizumab, in 7 of the 10 patients, exact data on prior immunotherapy for the treatment of MS prior to NTZ-PML development is known. Four were previously treated with interferon beta-1a, one had been treated interferon beta-1a and interferon beta-1b, and two had no prior immunotherapy. Of the remaining three patients, it is known that they were not previously treated with immunosuppressive therapy, but it is unknown whether they had used immunomodulatory drugs.

\section{Imaging characteristics of inflammation at PML diagnosis and during PML-IRIS phase}

\section{Global frequency of imaging signs of inflammation}

As per definition, all patients analyzed showed signs of inflammation already at time of PML diagnosis, with contrast enhancement seen in 9 out of 10 patients (90\%), and perivascular T2 lesions in 6 patients (60\%), among whom one did not display contrast enhancement. At the time of PML-IRIS, all patients (100\%) displayed contrast enhancement, and the proportion of patients with perivascular T2 lesions increased to 8 out of the 10 
patients $(80 \%)$. Perilesional edema was seen in only 1 patient at time of diagnosis $(10 \%)$, increasing to 4 (40\%) during PML-IRIS. Swelling with mass effect was absent in patients at diagnosis, increasing to 6 (60\%) during PML-IRIS.

\section{Characteristics of contrast enhancement}

At PML diagnosis and during PML-IRIS, contrast enhancement was seen at the border of the PML lesion (8 and 10 patients, respectively), outside of the PML-lesions (6 and 9 patients, respectively), and in the center of the PML lesion (2 and 5 patients, respectively).

Appearance of contrast enhancement was rarely noted to be homogenous (none at diagnosis, 1 during PML-IRIS), but either of punctate (5 at diagnosis, 8 during PML-IRIS), or of patchy (8 at diagnosis, 10 during PML-IRIS). Figures 2 and 3 show examples of different enhancement pattern (punctuate, patchy).

\section{Individual course of the patients and MRI lesion characteristics}

The individual course of lesion characteristics of the patients is shown in table 2. The clinical presentation including EDSS has not been systematically assessed during and after the PML/PML-IRIS disease course. One single patient (patient number 1) died, all other patients survived PML/PML-IRIS. One patient (patient number 7) stayed asymptomatic during the whole PML/PML-IRIS disease course. One patient (patient number 1) received single course of i.v. corticosteroids ( $1000 \mathrm{mg} /$ day for three days) directly after the diagnosis of inflammatory PML.

Comparing extent and distribution of contrast enhancement at diagnosis and at the PML-IRIS stage, nine out of ten patients showed new or persisting contrast-enhancement following the same pattern during PML-IRIS as seen at the time of PML diagnosis (seven patients with new contrast-enhancing lesions following a similar pattern and seven patients with persistence of the contrast enhancement from the time of diagnosis). The progression of contrast-enhancement at/during PML-IRIS stages was present in the center/at the border of the main lesion as well as in lesions outside the main PML lesion (Figure 3). In the one 
patient showing just perivascular T2 lesion as imaging sign suggestive of inflammation at the time of PML diagnosis, these perivascular T2 lesions started showing additional contrast enhancement, with associated edema and mass effect in other locations during the PMLIRIS phase. Figure 2 and 3 show examples of the inflammatory PML lesion characteristics at baseline and during follow-up. 


\section{DISCUSSION}

In this study, we systematically describe the imaging characteristics of "inflammatory PML" lesions, and we show that the vast majority of these patients continue to show similar signs of inflammation during PML-IRIS stages. Signs of inflammation, in particular contrastenhancement, seen on brain MRI have been described in approximately $30 \%$ of natalizumab-associated PML patients at the time of PML diagnosis, either in symptomatic or asymptomatic disease stages.[11,15,16,35] The pathophysiological background of these imaging signs suggestive of inflammation remained poorly understood for a long time. Recent histopathological data suggested that such inflammation at the time of PML diagnosis might be related to an immune response against the JC virus, similar to, but less severe than, in patients entering the PML-IRIS stage.[23,26,27] PML-IRIS lesions are characterized by inflammatory cell infiltrations including an abundance of CD8+ T cells and numerous macrophages. In addition, surprisingly high plasma cell numbers were reported in natalizumab-associated PML-IRIS by one histopathological case series, not noted in HIV associated PML.[27] Of importance to our study, natalizumab-associated inflammatory PML cases generally share these histopathological findings of PML-IRIS, including the high plasma cell numbers, albeit to a lesser extent.[27] This also refers to specific patters of inflammation, such as the observation of perivascular cuffing, observed PML-IRIS patients as well as in inflammatory PML patients.[26] Obviously, even in early PML stages, CD8+ cytotoxic T cells are able to attack the JC virus and control the PML disease activity.[36]

In fact, our in-vivo imaging study is in line with these histopathological data. In general, the vast majority of our patients showed a similar imaging pattern of inflammation at the time of PML diagnosis as during the PML-IRIS stage. Although the imaging pattern suggestive of inflammation remained similar during follow-up, the severity of inflammation increased at the PML-IRIS stage including new enhancing lesions, swelling, and perilesional edema. As such, imaging patterns of inflammation at the time of PML diagnosis and at the PML-IRIS stage likely are no distinct entities, but rather differ in their extent of inflammation. This supports experimental evidence that the inflammation seen at both stages of the same 
disease may share a similar underlying pathophysiology, representing the immune response to the causative $\mathrm{JC}$ virus to a variable extend.[27]

Comparing our present inflammatory PML patients to our recently published 'classic' NTZ-PML cohort without any imaging signs of inflammation, the time interval between PML diagnosis and PML-IRIS occurrence was longer for patients with "inflammatory" PML (66.5 days, range: 23-224 [table 1] versus 42 days, range 6-98 days). In addition, one of our inflammatory PML patients received i.v. corticosteroids directly of the diagnosis of inflammatory PML whereas 4 patients of the non-inflammatory PML cohort received corticosteroids < 30 days to PML-IRIS manifestation.[33] It remains unclear if this difference holds up in independent cohorts, and if this is of clinical relevance. However, it could have influenced the patient management.[37]

In general, the investigation of any link between the clinical outcome and the described MRI findings was not the aim of this study. Owing to the rather small size of our study, we were unable to link presence or absence of inflammation at time of PML diagnosis to clinical outcome, warranting larger studies and a prospective, multicentric approach. Furthermore, another open question is if patients with signs of inflammation on imaging should be treated differently as compared to patients with classical PML. Potential differences in the patient management could relate to the early administration of corticosteroids even before the patient is classified as PML-IRIS, or the use of measures of enhancing NTZ clearance depending on imaging characteristics (plasmapheresis/ immunoabsorption). Additional biomarkers such as virus specific antibody responses in blood, CSF, or T cell responses that classify and quantify the immune response against JCV at the time of PML diagnosis may potentially be useful tools for individualizing therapeutic regimens.[31,32,38,39]

This study has limitations. First of all, the number of patients in our study presenting with imaging signs suggestive of inflammation with a complete clinical and radiological follow-up until the PML-IRIS stage is rather small. Although these patients are well characterized in terms of patient management, treatment and co-morbidity, we cannot 
exclude that some of these aspects could have influenced the clinical and imaging presentation. Further studies including larger numbers of patients are needed to further support our results.

In conclusion, our study demonstrates that an imaging pattern suggestive of inflammation at the time of PML diagnosis in natalizumab-treated MS patients shares imaging characteristics of PML-IRIS in later disease stages. Many of these initial inflammatory PML lesions develop into sites of severe inflammation at PML-IRIS stage. This further supports histopathological and experimental data that this inflammation at the time of PML diagnosis is most likely based on a lymphocytic response against the $\mathrm{JC}$ virus due to an incomplete immune suppression during natalizumab treatment. 


\section{Acknowledgements}

The authors wish to thank all PML patients for agreeing to the use of their MRI images and (para)clinical data for research and education purposes. In addition, we wish to thank Professor Wolfgang Brück and Dr. Imke Metz (Department of Neuropathology, University Hospital Göttingen, Germany) for sharing their data and expertise on histopathology findings in natalizumab-associated PML-IRIS. FB is supported by the NIHR biomedical research centre at UCLH.

\section{Funding}

The MS Centre Amsterdam is funded by a program grant (14-358e) from the Stichting voor MS Research (Voorschoten, The Netherlands). CW was supported by a grant from the Hertie-Foundation (P1150063).

\section{Contributors}

MPW, MTW collected the data, analyzed the data and wrote the manuscript. FB, SF, BMJU, CW and JK interpreted the data and edited the manuscript. All authors reviewed and agreed on the final versions of the manuscript.

\section{Competing interest}

MPW has received consultancy fees from Biogen, Novartis and Roche. FB serves as a consultant for Bayer-Schering Pharma, Sanofi-Aventis, Biogen, Teva, Novartis, Roche, Synthon BV, Genzyme, Jansen Research. JK has accepted consulting fees from MerckSerono, TEVA, Biogen, Genzyme, and Novartis. BMJU has received consultancy fees from Novartis, Merck Serono, Biogen and Danone Research. MTW does not report any competing interest. The VUmc has received financial support for research activities from Bayer Schering Pharma, Biogen, Glaxo Smith Kline, Merck Serono, Novartis, and Teva. JE received 
consultancy fees and/ or lecture fees from Biogen, Genzyme, Teva, Merck and Novartis. The authors had full editorial control of the manuscript and provided their final approval of all content.

\section{Collaborators}

Bob W van Oosten and Chris H. Polman (VU University Medical Center, Amsterdam, The Netherlands), Dorine A Siepman and Rogier Hintzen (Erasmus MC, University Medical Center Rotterdam, The Netherlands), Jop Mostert (Rijnstate Hospital, Department of Neurology, Arnhem, The Netherlands), Wibe Moll (Maasstad Hospital, Rotterdam, The Netherlands), Alex EL van Golde (ZGT Hospital, Almelo, The Netherlands), Stephan TFM Frequin (St Antonius Hospital, Nieuwegein, The Netherlands), Paul AD Bouma (Tergooi, Blaricum, Hilversum, The Netherlands), Bénédicte Quivron ( $\mathrm{CH}$ Jolimont, La Louvière, Belgium), Jean Braeckeveldt (Epicura, Baudour, Belgium), Erik van Munster and Jeroen van Eijk (Department of Neurology, Jeroen Bosch Ziekenhuis, 's Hertogenbosch, The Netherlands), Thea Heersema (Department of Neurology, University Medical Center Groningen, Groningen, The Netherlands), Jaap de Graaf (Isala Hospital, Zwolle, The Netherlands). 


\section{References}

1. Maas RP, Muller-Hansma AH, Esselink RA, et al. Drug-associated progressive multifocal leukoencephalopathy: a clinical, radiological, and cerebrospinal fluid analysis of 326 cases. J Neurol 2016;263:2004-21.

2. Rudick R, Polman C, Clifford D, Miller D, et al. Natalizumab: bench to bedside and beyond. JAMA Neurol 2013;70:172-182.

3. Tan CS, Koralnik IJ. Progressive multifocal leukoencephalopathy and other disorders caused by JC virus: clinical features and pathogenesis. Lancet Neurol 2010;9:425437.

4. Brew BJ, Davies NW, Cinque P, Clifford DB, Nath A. Progressive multifocal leukoencephalopathy and other forms of JC virus disease. Nat Rev Neurol 2010;6: $667-79$.

5. Wijburg MT, van Oosten BW, Murk JL, Karimi O, Killestein J, Wattjes MP. Heterogeneous imaging characteristics of JC virus granule cell neuronopathy (GCN): a case series and review of the literature. $J$ Neurol 2015;262:65-73.

6. Winkelmann A, Loebermann M, Reisinger EC, Hartung HP, Zettl UK. Diseasemodifying therapies and infectious risks in multiple sclerosis. Nat Rev Neurol 2016;12:217-33

7. Wattjes MP, Rovira À, Miller D, et al. Evidence-based guidelines: MAGNIMS consensus guidelines on the use of MRI in multiple sclerosis--establishing disease prognosis and monitoring patients. Nat Rev Neurol 2015;11:597-606.

8. McGuigan C, Craner M, Guadagno J,et al. Stratification and monitoring of natalizumab-associated progressive multifocal leukoencephalopathy risk: recommendations from an expert group. J Neurol Neurosurg Psychiatry 2016;87:11725. 
9. Vågberg M, Axelsson M, Birgander R, et al. Guidelines for the use of magnetic resonance imaging in diagnosing and monitoring the treatment of multiple sclerosis: recommendations of the Swedish Multiple Sclerosis Association and the Swedish Neuroradiological Society. Acta Neurol Scand 2017;135:17-24.

10. Linda $\mathrm{H}$, Von HA. Presymptomatic diagnosis with MRI and adequate treatment ameliorate the outcome after natalizumab-associated progressive multifocal leukoencephalopathy. Front Neurol 2013;4:11.

11. Wattjes MP, Vennegoor A, Steenwijk MD, et al. MRI pattern in asymptomatic natalizumab-associated PML. J Neurol Neurosurg Psychiatry 2015;86:793-8.

12. Dong-Si T, Richman S, Wattjes MP, et al. Outcome and survival of asymptomatic PML in natalizumab-treated MS patients. Ann Clin Transl Neurol 2014;1:755-764.

13. Mc Govern EM, Hennessy MJ. Asymptomatic progressive multifocal leukoencephalopathy associated with natalizumab. J Neurol 2013;260:665-7.

14. Hodel J, Outteryck O, Dubron C, et al. Asymptomatic Progressive Multifocal Leukoencephalopathy Associated with Natalizumab: Diagnostic Precision with MR Imaging. Radiology 2016;278:863-72.

15. Yousry TA, Pelletier D, Cadavid D, et al. Magnetic resonance imaging pattern in natalizumab-associated progressive multifocal leukoencephalopathy. Ann Neurol 2012;72:779-87.

16. Richert N, Bloomgren $G$, Cadavid D, et al. Imaging findings for PML in natalizumabtreated MS patients. Mult Scler 2012;18(Suppl 4):27-8. Oral 99.

17. Wattjes MP, Vennegoor A, Mostert J, et al. Diagnosis of asymptomatic natalizumabassociated PML: are we between a rock and a hard place? J Neurol 2014;261:1139_ 43. 
18. Wattjes MP, Richert ND, Killestein J, et al. The chameleon of neuroinflammation: magnetic resonance imaging characteristics of natalizumab-associated progressive multifocal leukoencephalopathy. Mult Scler 2013;19:1826-40.

19. Wattjes MP, Wijburg MT, Vennegoor A, et al. Diagnostic performance of brain MRI in pharmacovigilance of natalizumab-treated MS patients. Mult Scler 2016;22:1174-83.

20. Phan-Ba R, Lommers E, Tshibanda L, et al. MRI preclinical detection and asymptomatic course of a progressive multifocal leucoencephalopathy (PML) under natalizumab therapy. J Neurol Neurosurg Psychiatry 2012;83:224-226.

21. Wattjes MP, Verhoeff L, Zentjens $W$, et al. Punctate lesion pattern suggestive of perivascular inflammation in acute natalizumab-associated progressive multifocal leukoencephalopathy: productive JC virus infection or preclinical PML-IRIS manifestation? J Neurol Neurosurg Psychiatry 2013;84:1176-7.

22. Hodel J, Darchis C, Outteryck O, et al. Punctate pattern: A promising imaging marker for the diagnosis of natalizumab-associated PML. Neurology 2016;86:1516-23.

23. Clifford DB. Neurological immune reconstitution inflammatory response: riding the tide of immune recovery. Curr Opin Neurol 2015;28:295-301.

24. Wattjes MP, Barkhof F. Diagnosis of natalizumab-associated progressive multifocal leukoencephalopathy using MRI. Curr Opin Neurol 2014;27:260-70

25. Schneider-Hohendorf T, Rossaint $\mathrm{J}$, Mohan $\mathrm{H}$, et al. VLA-4 blockade promotes differential routes into human CNS involving PSGL-1 rolling of T cells and MCAMadhesion of TH17 cells. J Exp Med 2014;211:1833-46.

26. Kleinschmidt-DeMasters BK, Miravalle A, Schowinsky J, Corboy J, Vollmer T. Update on PML and PML-IRIS occurring in multiple sclerosis patients treated with natalizumab. J Neuropathol Exp Neurol 2012;71:604-17. 
27. Metz I, Radue EW, Oterino A, et al. Pathology of immune reconstitution inflammatory syndrome in multiple sclerosis with natalizumab-associated progressive multifocal leukoencephalopathy. Acta Neuropathol 2012;123:235-245.

28. Tan IL, McArthur JC, Clifford DB, et al. Immune reconstitution inflammatory syndrome in natalizumab-associated PML. Neurology 2011;77:1061-1067.

29. Gheuens S, Smith DR, Wang X, et al. Simultaneous PML-IRIS after discontinuation of natalizumab in a patient with MS. Neurology 2012;78:1390-1393.

30. Post MJ, Thurnher MM, Clifford DB, et al. CNS-immune reconstitution inflammatory syndrome in the setting of HIV infection, part 1: overview and discussion of progressive multifocal leukoencephalopathy-immune reconstitution inflammatory syndrome and cryptococcal-immune reconstitution inflammatory syndrome. AJNR Am J Neuroradiol 2013;34:1297-307.

31. Antoniol C, Jilek S, Schluep M, et al. Impairment of JCV-specific T-cell response by corticotherapy: effect on PML-IRIS management. Neurology 2012;79:2258-64.

32. Berger JR. Steroids for PML-IRIS: a double-edged sword? Neurology 2009;72(17):1454-5.

33. Wattjes MP, Wijburg MT, Vennegoor A, et al. MR imaging characteristics of early PML-IRIS after natalizumab-treatment in MS patients. J Neurol Neurosurg Psychiatry 2016;87:879-84

34. Berger JR, Aksamit AJ, Clifford DB, et al. PML diagnostic criteria: Consensus statement from the AAN Neuroinfectious Disease Section. Neurology 2013;80:14308.

35. Post MJ, Yiannoutsos C, Simpson D, et al. Progressive multifocal leukoencephalopathy in AIDS: are there any MR findings useful to patient management and predictive of patient survival? AIDS Clinical Trials Group, 243 Team. AJNR Am J Neuroradiol 1999;20:1896-906. 
36. Du Pasquier RA, Kuroda MJ, Zheng Y, Jean-Jacque J, Letvin NL, Koralnik IJ. A prospective study demonstrates an association between JC virus-specific T lymphocytes and the early control of progressive multifocal leukoencephalopathy. Brain 2004; 127: 1970-1978

37. Hoepner R, Kolb EM, Dahlhaus S, et al. Predictors of severity and functional outcome in natalizumab-associated progressive multifocal leukoencephalopathy. Mult Scler $2017 ; 23: 830-835$

38. Warnke C, von Geldern G, Markwerth P, et al. Cerebrospinal fluid JC virus antibody index for diagnosis of natalizumab-associated progressive multifocal leukoencephalopathy. Ann Neurol 2014;76:792-801.

39. Warnke C, Wijburg MT, Hartung HP, Killestein J, Adams O, Wattjes MP. Application of the CSF JCV antibody index to early natalizumab-associated progressive multifocal leukoencephalopathy. J Neurol Neurosurg Psychiatry 2017 May 10, doi: 10.1136/jnnp-2016-315298. [Epub ahead of print] 


\section{Legends to the figures:}

\section{Figure 1}

Flow chart illustrating the patient selection and inclusion process.

\section{Figure 2}

T2 and T1 weighted images (with contrast administration) at the time of PML diagnosis (top row) and at the time of PML-IRIS stage (bottom row). The images at diagnosis ("inflammatory PML") show a subcortical and cortical lesion in the right frontal lobe showing contrast enhancement $(C, D)$ in addition to punctuate T2 lesions following a perivascular distribution that also enhance on $\mathrm{T} 1$ after contrast administration (A, B). These inflammatory PML lesions show different enhancement pattern such as punctuate (B) and patchy (D). At the time of PML-IRIS manifestation the PML lesions have increased in size and the contrast enhancement of the main PML lesion $(\mathrm{H}, \mathrm{I})$ as well as in and around the perivascular T2 lesions $(F, G)$ has also markedly increased. In addition, there are now signs of edema with mass effect around the PML lesions $(F, H)$.

\section{Figure 3}

Fluid attenuation inversion recovery (FLAIR), T2 and T1 weighted images (with contrast administration) at the time of PML diagnosis (top row), and at the time of PML-IRIS stage (bottom row). At the time of diagnosis there are multiple contrast enhancing punctuate T2 
lesions (punctuate enhancement pattern) with a perivascular distribution visible $(A-C)$. At PML-IRIS manifestation there is a massive increase in the number of contrast enhancing perivascular lesions and persistence of the contrast enhancement from the time of diagnosis $(D-F)$. The increase of punctuate lesions in number and size includes enhancing lesions in the main PML lesions as well as outside of the main PML lesion $(F)$. In addition, the main PML lesion had increased in size. 
Table 1: Demographic and clinical characteristics of the included patients

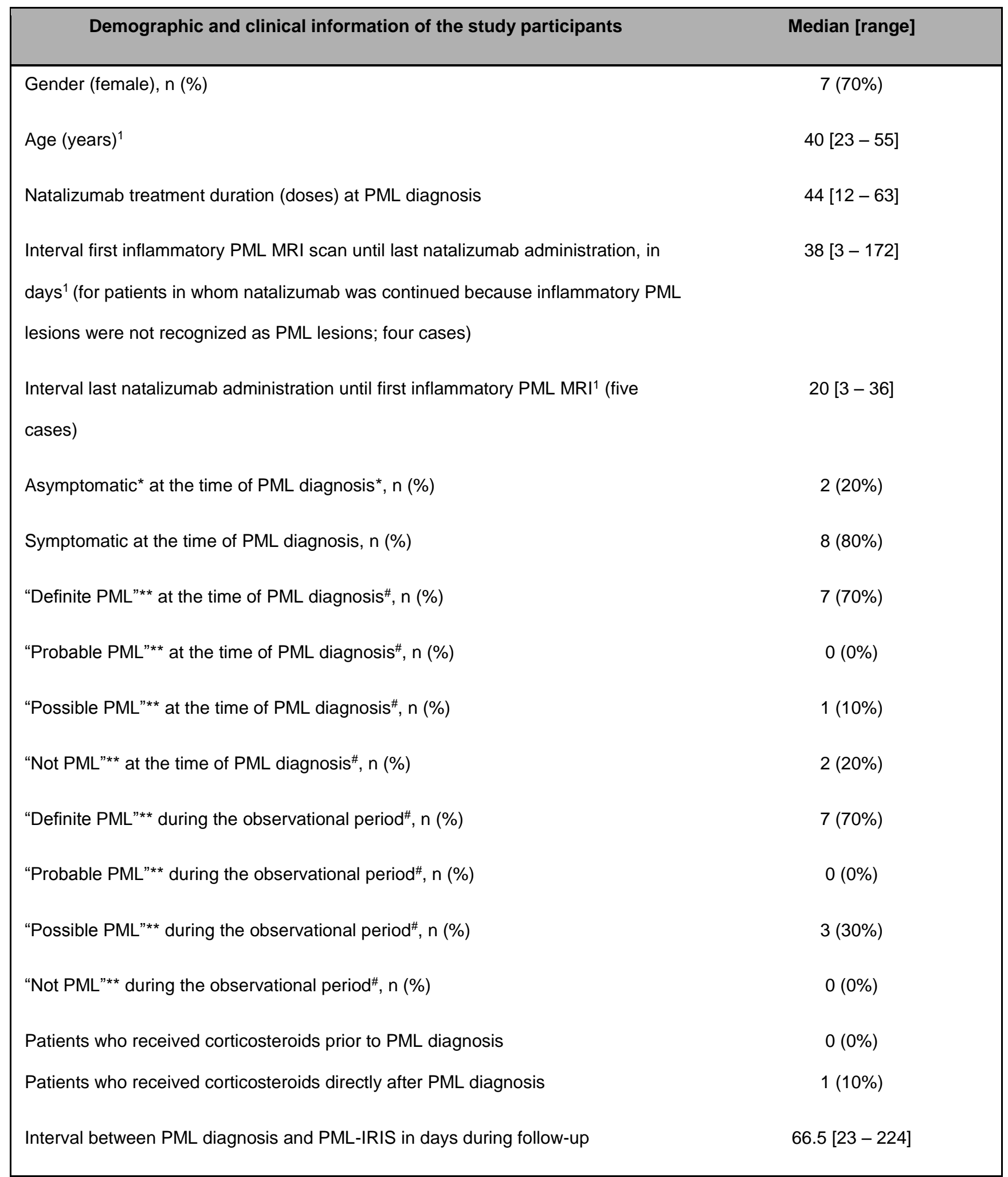

$\mathrm{PML}=$ progressive multifocal leukoencephalopathy, IRIS= immune reconstitution inflammatory syndrome

${ }^{1}$ data missing for one patient. 
${ }^{*}$ Asymptomatic PML is defined as no symptoms suggestive of PML

** "Definite PML": all patients had a clinical presentation and imaging findings suggestive of PML as well as JCV DNA in the CSF detected by PCR. "Probable PML": all patients were asymptomatic, had MRI lesion(s) suggestive of PML and JCV DNA in the CSF detected by PCR. "Possible PML": all patients had clinical symptoms suggestive of PML and MRI lesion(s) suggestive of PML but no JCV DNA detected in the CSF. "No PML": all patients had MRI lesion(s) suggestive of PML but no clinical symptoms suggestive of PML, no JCV DNA has been detected in the CSF.

\# According to American Academy of Neurology (AAN) PML diagnostic criteria [27]

\section{Table 2}




\begin{tabular}{|c|c|c|c|c|c|c|c|c|}
\hline \multirow[t]{2}{*}{ Patient } & \multirow[t]{2}{*}{ PML diagnosis $(n=10)$} & \multirow[t]{2}{*}{ PML-IRIS stage $(n=10)$} & \multicolumn{2}{|c|}{ Findings at PML-IRIS phase } & \multirow[b]{2}{*}{$\begin{array}{c}\text { Additional } \\
\text { enhancement } \\
\text { with a } \\
\text { different } \\
\text { pattern than } \\
\text { seen at Dx } \\
\text { (border, } \\
\text { center, } \\
\text { outside, } \\
\text { perivascular) }\end{array}$} & \multirow[b]{2}{*}{$\begin{array}{c}\text { Persistence } \\
\text { of } \\
\text { perivascular } \\
\text { T2 lesions } \\
\text { seen at Dx }\end{array}$} & \multirow[b]{2}{*}{$\begin{array}{l}\text { Appearance } \\
\text { of new } \\
\text { perivascular } \\
\text { T2 lesions }\end{array}$} & \multirow[b]{2}{*}{$\begin{array}{l}\text { New edema } \\
\text { or mass effect }\end{array}$} \\
\hline & & & $\begin{array}{l}\text { Persistence } \\
\text { of } \\
\text { enhancement } \\
\text { seen at } D x\end{array}$ & $\begin{array}{c}\text { New } \\
\text { enhancement } \\
\text { in same } \\
\text { pattern as Dx } \\
\text { (border, } \\
\text { center, } \\
\text { outside, } \\
\text { perivascular) }\end{array}$ & & & & \\
\hline 1 & $\begin{array}{l}\text { Contrast enhancement in border of the } \\
\text { PML lesions and enhancing perivascular } \\
\text { T2 lesions }\end{array}$ & $\begin{array}{l}\text { Persistent enhancing lesions from PML } \\
\text { diagnosis. New enhancing lesions with a } \\
\text { similar pattern. }\end{array}$ & $y$ & $y$ & $\mathrm{~N}$ & Y & $\mathrm{n}$ & $\mathrm{n}$ \\
\hline 2 & $\begin{array}{l}\text { Contrast enhancement in the center and } \\
\text { border of the PML lesions }\end{array}$ & $\begin{array}{l}\text { Persistent enhancing lesions from PML } \\
\text { diagnosis. New enhancing lesions with a } \\
\text { similar pattern and enhancing } \\
\text { perivascular T2 lesions. }\end{array}$ & $y$ & $y$ & Y & - & $y$ & $\mathrm{n}$ \\
\hline 3 & $\begin{array}{l}\text { Contrast enhancement in the border of } \\
\text { the PML lesions and enhancing } \\
\text { punctuate T2 lesions adjacent to the }\end{array}$ & $\begin{array}{l}\text { Enhancement from time of diagnosis } \\
\text { disappears during follow-up. New } \\
\text { contrast enhancing lesions following- } \\
\text { same pattern as at diagnosis, plus }\end{array}$ & $\mathrm{n}$ & $y$ & $\mathrm{n}$ & Y & $y$ & y \\
\hline
\end{tabular}




\begin{tabular}{|c|c|c|c|c|c|c|c|c|}
\hline & main PML lesion & swelling with mass effect. & & & & & & \\
\hline 4 & $\begin{array}{l}\text { Punctuate contrast enhancement } \\
\text { adjacent to the main PML lesion and } \\
\text { with a perivascular spread }\end{array}$ & $\begin{array}{l}\text { Persistent enhancing lesions from PML } \\
\text { diagnosis. New enhancing lesions in the } \\
\text { border of the PML lesions, plus swelling } \\
\text { with mass effect. }\end{array}$ & $y$ & $\mathrm{n}$ & $\mathrm{Y}$ & Y & $\mathrm{n}$ & $\mathrm{y}$ \\
\hline 5 & $\begin{array}{l}\text { Contrast enhancement in the border of } \\
\text { the PML lesions and adjacent to the } \\
\text { PML lesions }\end{array}$ & $\begin{array}{l}\text { Persistent enhancing lesions from PML } \\
\text { diagnosis. New enhancing lesions with a } \\
\text { similar pattern and new enhancing } \\
\text { lesions in the center of the PML lesions } \\
\text { plus swelling with mass effect. }\end{array}$ & $y$ & $y$ & $\mathrm{Y}$ & - & $\mathrm{n}$ & $y$ \\
\hline 6 & $\begin{array}{l}\text { Contrast enhancement in the center, } \\
\text { border and outside of the PML lesions, } \\
\text { enhancing punctuate T2 lesions and } \\
\text { perilesional edema }\end{array}$ & $\begin{array}{l}\text { Persisting enhancement and edema. } \\
\text { New enhancing lesions with a similar } \\
\text { pattern and swelling with mass effect. }\end{array}$ & $\mathrm{y}$ & $\mathrm{y}$ & $\mathrm{N}$ & Y & $\mathrm{n}$ & $\mathrm{y}$ \\
\hline 7 & $\begin{array}{l}\text { Contrast enhancement in the border and } \\
\text { outside of the PML lesion with } \\
\text { enhancing perivascular T2 lesions }\end{array}$ & $\begin{array}{l}\text { Persisting enhancement. New } \\
\text { enhancing lesions with a similar pattern } \\
\text { and new enhancing lesions outside of } \\
\text { PML lesions, and new perilesional } \\
\text { edema and swelling with mass effect. }\end{array}$ & $\mathrm{y}$ & $y$ & $\mathrm{Y}$ & Y & $\mathrm{n}$ & $y$ \\
\hline
\end{tabular}




\begin{tabular}{|c|c|c|c|c|c|c|c|c|}
\hline 8 & $\begin{array}{l}\text { Contrast enhancement in the border of } \\
\text { the PML lesion with enhancing } \\
\text { perivascular T2 lesions }\end{array}$ & $\begin{array}{l}\text { Enhancement from time of diagnosis } \\
\text { disappears during follow-up. New } \\
\text { contrast enhancing lesions following- } \\
\text { same pattern as at diagnosis and new } \\
\text { enhancing lesions in the center and } \\
\text { outside of the PML lesion, plus } \\
\text { perilesional edema. }\end{array}$ & $\mathrm{n}$ & $y$ & $\mathrm{Y}$ & $\mathrm{Y}$ & $\mathrm{n}$ & $\mathrm{y}$ \\
\hline 9 & $\begin{array}{l}\text { Contrast enhancement in the border of } \\
\text { the PML lesion }\end{array}$ & $\begin{array}{l}\text { Slight diminishment of earlier } \\
\text { enhancement, new punctuate enhancing } \\
\text { lesions outside of the PML lesion }\end{array}$ & $y / n$ & $\mathrm{n}$ & $\mathrm{Y}$ & - & $\mathrm{n}$ & $\mathrm{n}$ \\
\hline 10 & Perivascular T2 lesions & $\begin{array}{l}\text { Contrast enhancement of perivascular } \\
\text { T2 lesions and enhancement in border } \\
\text { and outside of the PML lesion, plus } \\
\text { perilesional edema and swelling with } \\
\text { mass effect }\end{array}$ & - & - & $\mathrm{Y}$ & $\mathrm{Y}$ & y & $\mathrm{y}$ \\
\hline
\end{tabular}

PML: progressive multifocal leukoencephalopathy, IRIS: immune reconstitution inflammatory syndrome. Dx: diagnosis, y: yes, n: no, n/a: not applicable. 